\title{
NILAI KEWAJIBAN TERHADAP DIRI SENDIRI DALAM NOVEL TAK SEMPURNA KARYA FAHD DJIBRAN FEAT BONDAN PRAKOSO DAN FADE2BLACK
}

\author{
Kristin Dwi Wulandari \\ Kantor Kecamatan Sukodadi, Lamongan \\ Telp. 081249588463
}

\begin{abstract}
Abstrak: Penelitian ini dilaksanakan dengan tujuan untuk mengetahui kewajiban terhadap diri sendiri dalam novel Tak Sempurna.Sumber data penelitian ini bersumber dari novel Tak Sempurna karya Fahd Djibran, Bondan Prakoso feat Fade2black.Teknik Pengumpulan data yang digunakan dalam penelitian ini adalah teknik membaca dan pencatatan.Teknik analisis data yang digunakan dalam penelitian ini adalah teknik analisis isi.Instrumen penelitian ini adalah peneliti. Hasil penelitian menunjukkan bahwa kewajiban terhadap diri sendiri dalam novel Tak Sempurnaberupa bersyukur, semangat tinggi, belajar, keyakinan, penyesalan
\end{abstract}

Kata kunci: kewajiban terhadap diri sendiri

Abstract: This research was conductedin order to determinethe obligationsof selfin the novel Imperfect. Source of research datais sourced from the novel Imper fectworks Fahd Djibran, Bondan Prakoso feat Fade2Black. Data collection techniques used in this researchis the technique of reading and recording. The data analysis technique used in this research iscontent analysis techniques. The instrumentof this study are researchers. The results showed that the obligation to selfin the novel Imperfect be grateful, be highly motivated, learning, faith, regrets

Keywords: an obligationto yourself

\section{PENDAHULUAN}

Moral sebagai pengejawentahan sosok manusia tentang apa yang harus dilakukan dan dikerjakannya mempunyai sejarah panjang. Sejarah itu bergerak sepanjang perjalanan manusia itu sendiri dan mengalami perkembangan dan signifikasi dengan perubahan zaman. Perkembangan dan perubahan yang disebabkan oleh muunculnya masalah etika dan moral yang baru dan berat. Terutama karena derasnya perkembngan ilmu dan pengetahuan dan teknologi serta sosial budaya masyrakat moderen yang penuh dengan perubahan (Muchsin, 2002:9).

Oleh karena itu pernyataan spesifik seperti apa yang disebut "yang baik", atau yang "tidak baik ",apa yang pantas", dan apa pula yang "tidak pantas" serta bagaimana cara mengetahuinya merupakan persoalaan yang uregen untuk dijawab agar dapat dilihat aktivitas pembenaran moral yang sesungguhnya bagi manusia (Alfan, 2013 : 26).

Nilai-nilai membantu manusia untuk membentuk pola suatu fakta dan mengidentifikasikan keberartiaan dan (makna) fakta tersebut. Gordon 
menyatahkan pentingnya untuk mengakui hak tersebut, apabila, manusia mengetahui dan perbedaan fakta yang dinilai. Praktik kehidupan yang efektif, diperoleh melalui penggunaan nilai-nilai atau prinsip-prinsip faktual.Gordon mempercayai bahwa dari perbedaan yang penuh kehati-hatian, pengetahuan faktual dapat mengembangkan ilmu pengetahuan dalam dimensi sosial (Alfan, 2013: 21).

Imam Al Ghazali menyatakan keberadaan nilai moral ini dalam "'lubuk hati “ (Al Qolbu) serta menyatu/bersatu raga di dalamnya menjadi suara hati dan hati nurani(the conscience of man). Mirip dengan pandangan Fraenkel ialah Rokeah, yang menyatahkan bahwa nilai merupakan sesuatu yang berharga, yang dianggap, bernilai, adil, baik dan indah serta menjadi pedoman atau pegangan diri (Hamid, 2012:27).

Vaule berasal dari Bahasa Latin, 'valere' secara harfiah berarti baik/buruknya yang kemudian artinya diperluas menjadi segala sesuatu yang disenangi, diinginkan, dicita-cita dan disepakati. Nilai berada dalam hati nurani dan pikiran sebagai suatu keyakinan atau kepercayaan. Nilai harus dibina terus menerus karena nilai merupakan aspek masalah kewajiban yang timbul tenggelam atau pasang surut (Hamid, 2012:50).

Nilai merupakan realitas abstrak yang dapat dirasakan dalam diri manusia masing-masing sebagai daya pendorong atau prinsip-prinsip yang menjadi pedoman dalam hidup. Nilai yang bersifat abstrak ini dapat diketahui dari tiga realitas, yaitu pola tingka laku, pola berpikir dan sikap-sikap seoarang pribadi atau kelompok (Kaswari, 1993 :20).

Moral adalah kualitas perbuatan manusia yang menunjukkkan bahwa perbuatan itu benar atau salah, baik atau buruk. Moral mencakup pengertian tentang baik buruknya perbuatan manusia(Poespoprodjo, 1998 : 118).

Moral adalah nilai-nilai dan normanorma yang menjadi pegangan bagi seseorang atau suatu kelompok masyrakat dalam mengatur tingkah lakunya(Muchsin,2002: 13).

Moral adalah sopan santun, segala sesuatu yang berhubungan dengan etiket atau sopan santun. Moral dapat berasal dari sumber tradisi adat, agama atau sebuah ideologi atau gabungan beberapa( Purwanto, 2007: 4).

Kant mengatakan bahwa meskipun pelaksanaan moral berbeda-beda karena keadaan yang berbeda, orang yang baik adalah orang bertindak dengan suatu asumsi, bahwa ada standar moral yang obyektif tanpa pamrih. Satu-satunya yang baik tanpa kualifikasi dan tanpa adanya pembatasan adalah kehendak yang baik. Menurut Kant, seseorang menjadi orang yang baik, orang yang bermoral baik karena merasa wajib berbuat baik, bukan karena merasa wajib berbuat baik, bukan karena ia mempunyai kecenderungan untuk menjadi baik. Jadi motif untuk menjadi bermoral bukan kecenderungan, melainkan wajib.

Standar moral manusia banyak ditentuhkan oleh tingkat perkembangan sosial, inteligensi dan ilmu pengetahuan yang berkembang. Moralitas tumbuh dan berkembang dalam kehidupan manusia sebagai pembuka bagi kehidupan yang lebih maju ke arah kehidupan yang membahagiakan dan penuh makna (Alfan, 2013 : 26).

Moral dalam karya sastra dapat dijadikan sebagai bahan pelajaran yang menarik. Dalam karya sastra, "moral kadang-kadang diidentikan pengertiannya dengan tema walau selalu menyaran maksud yang sama',(Nurgiyantoro, 2009 : 320). Hal ini dikarenakan moral dalam karya sastra telah dikonotasikan dengan kebaikan-kebaikanyang direpresentasikan 
di dalamnya. Paradigma ini timbul oleh presepsi pembaca sehingga dari pengamatan tersebut ada yang menyamakan moral dengan tema (Sutardi, 2011: 41).

Bagi Kant, perbuatan yang mempunyai nilai moral adalah perbuatan yang dilaksanakan atas dasar kesadaran akan wajib, yaitu berbuat sedemikian rupa sehingga kewajiban untuk bertindak untuk dapat berlaku pada orang lain dapat berlaku umum. Dalam bertindak, seseorang akan melakukan pertimbanganpertimbangan yang menjadi dasar perbuatan inilah yang menjadi hukum. Kesadaran akan hukum moral ini akan menimbulkan rasa wajib, sehingga manusia akan bertindak sesuai dan berdasarkan wajib (Endang, 1997 : 55).

Karya sastra sering dikatakan sebagai 'tulisan yang indah '. Karya sasstra juga dikaitkan sebagai budi pekerti. Pernyataan ini memberikan penegasan bahwa sastra sebagai karya yang indah dan bermanfaat bagi pembaca. Masyarakat yang membaca karya sastra akan mendapat kesenangan dari tulisan yang indah dan mengharukan, juga mendapatkan pengetahuanpengetahuan yang tidak pernah disadari keberadaannya di sekeliling (Amanuddin,2011: 34).

Sudjiman (1998:53) mengatakan bahwa novel adalah prosa rekaan yang menyuguhkan tokoh dan menampilkan serangkain peristiwa serta latar secara tersusun, novel sebagai karya imaginative mengungkapkan aspek-aspek kemanusian yang mendalam dan menyajikan secara halus. Novel tidak hanya sebagai alat hiburan, tetapi juga sebagai bentuk seni yang mempelajari, meneliti segi kehidupan dan nilai-nilai baik buruk (moral) dalam kehidupan ini mengarahkan kepada pembaca tentang budi pekerti yang luhur.
Novel Tak Sempuna ini menceritakan tentang kehidupan anak sekolah yang tak sempurna.Dikehidupan keluarga kurang mendapatkan kasih sayang. Di sekolah mereka mengagap sekolah adalah tempat sampah bagi semua kebusukan dunia. Disekolah pertama kali mengenal hampir semua kata kata kotor , umpatan dan makian, mengenal pada video-video porno, lalu mengajari rokok, minum-minuman dan mencoba obat obatan. Disekolah orangorang dipanggil nama binatang biasa saja. Guru-guru kebanyakan dari mereka munafik dan menyebalkan mereka mengajari kami kebaikan-kebaikan yang tak pernah merekah contohkan dalam tindakantolol,bego,monyet, banci, ngepit, bangsat itu sebutan masing-masing nama dari mereka. Dengan keadaan itu, mereka mencari kepuasan diluar dengan melakukan tawuran.

Kewajiban terhadap diri sendiri. Manusia adalah makhluk individu sekaligus makhluk sosial. Sebagai makhluk individu manusia mempunyai kewajiban dan tugas-tugas terhadap dirinya sendiri, sedangkan sebagai makhluk sosial manusia myempunyai tugas-tugas dan kewajiban terhadap orang lain dan lingkungannya. Apabila menjalankan kewajiban terhadap diri sendiri dengan baik dalam arti hidup layak dan wajar, ia masih mempunyai arti dalam hidupnya. Akan tetapi seseorang yang melanggar dan menyalahi kewajiban terhadap dirinya sendiri, adalah orang tdak berharga sama sekali. Meskipun ia tidak mengganggu orang lain meskipun seseorang itu be bas menentuhkan hidupny sendiri, tetapi ia menghancurkan dirinya sendiri.

Kewajiban manusia yang universal ialah kewajiban yang yang berhubungan dengan pengaturan hidupnya sesuai dengan kewajiban moral. Manusia harus meneliti diri sendiri apakah prinsip- 
prinsip moral yang telah dientuhkan betul-betul murni tidak mengingkari moral, apakah tindakannya sesuai denga hukum moral. Dasar atau prinsip kewajiban terhadap diri se ndiri adalah self-mastery, penguasaan terhadap diri sendiri, pengendalian diri.Penguasaan terhadap diri sendiri merupakan kewajiban yang tertinggi pada diri sendiri, maka manusia harus dapat mempertahankan penguasaan terhadap diri sendiri ini.

\section{METODE PENELITIAN}

Penelitian ini menggunakan penelitiaan kualitatif yang bersifat deskriptif karena data yang digunakan bukan dalam bentuk angka, tetapi memanfaatkan cara-cara penafsiran serta menyajikan dalam bentuk deskripsi dan hasilnya berupa kalimat tertulis (Ratna,2013:46). Sumber data adalah novel Tak Sempurna karya Fahd Djibran, Bondan Prakoso feat Fade2black. Metode pengumpulan data mengunakan teknik membaca dan pencatatan data Disebut teknik membaca dan pencatatan karena peneliti membaca dan mempelajari dengan teliti teks yang terdapat dalam novel Tak Sempurna yang berkaitan dengan rumusan masalah diatas. Analisis data menggunakan teknik analisis isi. Dasar pelaksanaan analisis isi adalah penafsiran. Apabila proses penafsiran dalam penelitiaan kualitatif memberikan perhatiaan pada situasi alamiah, maka dasar penafsiran dalam analisis isi memberikan perhatiaan pada isi pesan(Ratna,2013:49). Adapun langkahlangkah kongkret analisis data dalam penelitian ini adalah untuk mengetahui kewajiban terhadap diri sendiri dalam novel Tak Sempurna. Intrument dalam penelitian ini adalah peneliti.

\section{PEMBAHASAN}

\section{Kewajiban Terhadap Diri Sendiri}

Manusia adalah makhluk individu sekaligus makhluk sosial. Sebagai makhluk individu manusia mempunyai kewajiban dan tugas-tugas terhadap dirinya sendiri, sedangkan sebagai makhluk sosial manusia mempunyai tugas-tugas dan kewajiban terhadap orang lain dan lingkungannya. Apabila menjalankan kewajiban terhadap diri sendiri dengan baik dalam arti hidup layak dan wajar, ia masih mempunyai arti dalam hidupnya. Akan tetapi seseorang yang melanggar dan menyalahi kewajiban terhadap dirinya sendiri, adalah orang tidak berharga sama sekali. Meskipun ia tidak mengganggu orang lain meskipun seseorang itu bebas menentuhkan hidupnya sendiri, tetapi ia menghancurkan dirinya sendiri.

Kewajiban manusia yang universal ialah kewajiban yang yang berhubungan dengan pengaturan hidupnya sesuai dengan kewajiban moral. Manusia harus meneliti diri sendiri apakah prinsipprinsip moral yang telah ditentuhkan betul-betul murni tidak mengingkari moral, apakah tindakannya sesuai denga hukum moral. Dasar atau prinsip kewajiban terhadap diri sendiri adalah self-mastery, penguasaan terhadap diri sendiri, pengendalian diri.

Penguasaan terhadap diri sendiri merupakan kewajiban yang tertinggi pada diri sendiri, maka manusia harus dapat mempertahankan penguasaan terhadap diri sendiri ini. Untuk itu dibutuhkan disiplin dan mendisiplinkan diri sendiri agar perbuatan manusia dapat terlaksana dengan baik. Disiplin adalah pragmatis, yang terjadi, karena manusia yang bersifat hati-hati. Disiplin yang berhubungan dengan hukum moral, yaitu disiplin moral, mempunyai tugas untuk mengontrol apakah tindakan manusia ini sesuai dengan hukum moral. Disiplin 
moral inilah yang mewajibkan manusia untuk mewujudkan kewajiban terhadap diri sendiri. Seseorang yang mendisiplinkan diri secara moral dapat menguasai diri sendiri. Oleh karena itulah maka disiplin moral harus ditumbuhkembangkan sehingga manusia mempunyai kebiasaan untuk menilai, mana yang baik secara moral dan mana yang kurang baik.

Manusia juga mempunyai kewajiban untuk senantiasa memelihara hidupnya, meskipun kewajiban ini bukan merupakan kewajiban yang terbesar, sebab yang terpenting adalah agar dapat hidup secara terhormat. Yang membuat manusia merasa hidup adalah aktivitas, kesibukan bukan berarti kesibukan bersenang-senang, tetapi kesibukan yang memberikan arti hidup. Terdapat pada kutipan di bawah ini :

Tak ada yang lebih buruk?Aku bertanya dalam hati.Aku bersyukur kepada Tuhan. Tapi, ya Tuhan..., ini bener-bener buruk! Aku sempat berpikir mungkin akan lebih baik aku meninggal dalam kecelakaan itu, tapi Tuhan mengiginkan aku tetap hidup(Djibran, 2013: 85).

Berdasarkan kutipan di atas kewajiban terhadap diri sendiri, Rama bersyukur kepada Tuhan atas apa yang dialami dalam kecelakaan tawuran itu, biarpun sempat berpikir untuk mati. Tetapi Tuhan masih memberikan kehidupan pada Rama.

Aku mulai menemukan gambaran lain tentang masa depan. Suatu kali aku pernah menyaksikan tayangan telivisi tentang seorang laki-laki yang kehilangan dua kakinya dalam sebuah kecelakaan kerja, tetapi pada akhirnya tak menyurutkan semangatnya, tak menyuramkan masa depannya.Lelaki itu justru menjadi pengusaha sukses yang membuat siapapun iri melihatnya. Aku juga melihat contoh baik lainnya : Seorang General Manager sebuah perusahaan multinasional memimpin rapat-rapat besar dan menjadi pembicara diseminar-seminar Internasional dari atas kursi roda-dengan kedua kakinya diamputasi. Aku juga bisa seperti mereka, bisikku dalam hati. Mencoba menghibur diri (Djibran, 2013 : 91).

Berdasarkan kutipan di atas Rama mempunyai kewajiban pada dirinya, agar tidak putus asa agar mempunyai semangat tinggi, melihat banyak contoh orang-orang yang mempunyai kekurangan, tapi mereka juga tidak putus asa malah mereka mempunyai semangat yang tinggi untuk menjadi sukses.

Mulai sekarang, kami harus berani mengunakan pemahaman kami sendiri! Menjadi tuan bagi kehendak, pikiran, dan tindakan kami sendiri! Dengan begitu, mungkin kami akan jadi pelajar yang benar-benar Tak Terkalahkan-tapi bukan soal tawuran(Djibran, 2013 : 122).

Berdasarkan kutipan di atas kewajiban terhadap diri sendiri seorang pelajar adalah belajar. Belajar dengan baik supaya menjadi pelajar yang tak terkalahkan pelajar yang pintar, rajin dan berwawasan. Dan bukan menjadi seorang pelajar suka tawuran.

Gue yakin kalo kita benar-benar mau berubah, mereka juga mau bantu kita buat mengakhiri semua ketololan ini.' Tanri mengangguk. Goris mengangguk. Anakanak menganggukan kepala mereka tersenyum (Djibran, 2013:121)

Berdasarkan kutipan di atas kesadaran Rama bersama temantemannya Tanri, Goris dan lainnya mempunyai kewajiban terhadap dirinya sendiri untuk merubah menjadi lebih baik, menghilangkan tradisi tawuran yang selama ini mereka lakukan.

Aku kembali terduduk di kursi roda.Papa menghembuskan napas panjang."Nggak apa-apa. Nanti kita coba lagi, " Katanya. Tenang.Aku mengangguk lemah.Agak putus asa." Kamu masih punya masa depan, Ram." Kata Papa." Kamu ingin kembali sekolah, kan?'Imbuhnya. Aku mengangguk merasa yakin. Aku ingin mencoba berdiri lagi. Tapi papa terlanjur mendorong kursi rodaku (Djibran, 2013 : 145)

Berdasarkan kutipan di atas adanya keyakinan pada diri Rama, untuk itu dia mempunyai kewajiban terhadap dirinya sendiri berlatih berjalan. Agar 
kepulihannya dari kecelakan yang mengakibatkan kakinya diamputasi akibat terlindas mobil saat tawuran.

Aku merasa bersalah membohongi Bunga. Sebenarnya aku pernah sekali mencoba putaw. Waktu masih zaman kegelapan. Untung aku tidak menikmatinya, hanya coba-coba. Setelah itu tidak pernah lagi. Aku bersyukur tak menjadi kecanduan (Djibran, 2013 : 187).

Berdasarkan kutipan di atas penyesalan Rama kepada Bunga karena dia membohonginya.Karena sebelumnya pernah memakai putaw dan tanpa memberitahu Bunga. Tapi itu semua sudah berlalu, dan pada akhirnya Rama mempunyai kesadaran tentang kewajiban terhadap dirinya sendiri untuk merubah dan berhenti memakai.

Ya kalo nggak berhenti bisa lebih parah lagi Ris mungkin giliran lo yang jadi korban . Mau sampe kapan coba berantem terus?" Suara santi terdengar tegas (Djibran, 2013 : 197).

Berdasarkan kutipan di atas himbauan Santi kepada Goris agar dia mempunyai kewajiban terhadap diri sendiri, berhenti melakukan tawuran yang selama ini sangat merugikan.

\section{SIMPULAN}

Dalam novel Tak Sempurna ditemukan kewajiban terhadap diri sendiri antara lain bersyukur, semangat tinggi, kesadaran, belajar, penyesalan dan keyakinan. Kewajiban terhadap diri sendiri dengan baik dalam arti hidup layak dan wajar, ia masih mempunyai arti dalam hidupnya. Manusia juga mempunyai kewajiban untuk senantiasa memelihara hidupnya, meskipun kewajiban ini bukan merupakan kewajiban yang terbesar, sebab yang terpenting adalah agar dapat hidup secara terhormat. Yang membuat manusia merasa hidup adalah aktivitas, kesibukan bukan berarti kesibukan bersenangsenang, tetapi kesibukan yang memberikan arti hidup.

\section{DAFTAR RUJUKAN}

Alfan, Muhammad. 2013. Pengantar Filsafat Nilai. Bandung: Pustaka Setia.

Aminuddin.2011. Pengantar Apresiasi Sastra. Bandung: Sinar Baru.

Asdi, Daruni Endang. 1997. Imperatif Kategoris dalam Filsafat Moral Immanuel Kant. Yogyakarta: Lukman Ofset.

Bertens, K. 2004. Etika. Jakarta: Kompas Gramedia.

Djibran, Fahd. 2013. Tak Sempurna. Jakarta. Kurniaesa Publishing.

Hamid, Darmadi. 2012. Dasar Konsep Pendidikan Moral. Bandung: Alfabeta.

Koentjaraningrat. 1977. Beberapa Antropologi Sosial. Jakarta. Dian Rakyat.

Muchsin. 2002. Menggagas Etika dan Moral. Surabaya: Adis Surabaya.

Poespoprodjo,W. 1998. Filsafat Moral. Bandung. Pustaka Grafika.

Purwanto, Yudi. 2007. Etika Profesi. Refika Adita.

Ratna, Kutha Nyoman. 2004. Penelitian Sastra. Denpasar. Pustaka Pelajar

Sutardi. 2011. Apresiasi Sastra. Lamongan: Pustaka Ilalang. 